Vol 5. No 1. Februari 2020

ISSN 2580-5029

\title{
Eksplorasi Jenis Jamur Makroskopis di Kawasan Bukit Gatan Kabupaten Musi Rawas Provinsi Sumatera Selatan
}

\author{
Larseh Putri Anggraini ${ }^{1}$, Harmoko ${ }^{2 *}$, Nopa Nopiyanti ${ }^{3}$ \\ 1,2,3 Program Studi Pendidikan Biologi STKIP PGRI Lubuklinggau, Jl. Mayor Toa Kel. Air Kuti Kec. \\ Lubuklinggau Timur 1 Kota Lubuklinggau 31628 \\ Corresponding Email: putroharmoko@gmail.com
}

\begin{abstract}
This study aims to determine the types of macroscopic fungi in Bukit Gatan, Musi Rawas Regency, and Abiotic Factors found in Bukit Gatan, Musi Rawas Regency. This research is descriptive, direct observation at the location of Bukit Gatan, Musi Rawas Regency by using the method of exploring with one hiking trail. Data were analyzed descriptively qualitatively. The type of fungus in the hiking trail are 2 divisions namely Basidiomycota and Ascomycota. The Basidiomycota Division found 7 orders, 11 families, 14 genera and 18 species, namely Pleurotus ostreatus, Pleurotus pulmonarius, Leptiota brunneoincarnata, Marasmius candidus, Schizophyllum commune, Entoloma procerum, Ganoderma sp, Ganoderma lucidum, Earliella scabrosa, Lentinus triginus, Lentinus strigosus, Trametes pubescens, Hirchioporus abietinus, Auricularia auricula, Geastrum saccatum, Clitocybe salmonilamella, Phallus indusiatus, Coltricia cinamomea, and Coltricia perennis. Ascomycota Division produces 2 orders, 2 families, 3 genera and 3 species namely Cookeina sulcipes, Daldinia conentria, and Xylaria longipes. The abiotic factors are the temperature of $29-31{ }^{\circ} \mathrm{C}$, $\mathrm{pH}$ between 67, humidity of 30-70\%, light intensity of 200 lux and height of 72-241 masl.
\end{abstract}

Keywords:Macroscopic Mushroom, Gatan Hill, South Sumatra, Waterfall

\begin{abstract}
ABSTRAK
Penelitian ini bertujuan untuk mengetahui jenis-jenis jamur makroskopis di Bukit Gatan Kabupaten Musi Rawas, serta Faktor Abiotik yang terdapat pada Bukit Gatan Kabupaten Musi Rawas. Penelitian ini bersifat deskriptif, observasi langsung di lokasi Bukit Gatan Kabupaten Musi Rawas dengan menggunakan metode jelajah dengan satu jalur pendakian. Data dianalisis secara deskriptif kualitatif. Jenis jamur yang ditemukan di jalur pendakian yaitu 2 divisi yaitu Basidiomycota dan Ascomycota. Divisi Basidiomycota didapatkan 7 ordo, 11 famili, 14 genus dan 18 spesies yaitu Pleurotus ostreatus, Pleurotus pulmonarius, Leptiota brunneoincarnata, Marasmius candidus, Schizophyllum commune, Entoloma procerum, Ganoderma sp, Ganoderma lucidum, Earliella scabrosa, Lentinus triginus, Lentinus strigosus, Trametes pubescens, Hirchioporus abietinus, Auricularia auricula, Geastrum saccatum, Clitocybe salmonilamella, Phallus indusiatus, Coltricia cinamomea, dan Coltricia perennis. Divisi Ascomycota didapatkan 2 ordo, 2 famili, 3 genus dan 3 spesies yaitu Cookeina sulcipes, Daldinia conentria, dan Xylaria longipes. Faktor abiotik tersebut yaitu suhu berkisar $29-31^{\circ} \mathrm{C}$, pH berkisar 6-7, kelembaban udaran berkisar 30-70\%, intensitas cahaya 200 lux dan ketinggian 72-241 mdpl.
\end{abstract}

Kata Kunci: Jamur Makroskopis, Bukit Gatan, Sumatera Selatan, Air Terjun. 


\section{PENDAHULUAN}

Indonesia merupakan Negara tropis yang memiliki sumber daya alam yang kaya akan keanekaragaman hayati salah satunya yaitu jamur. Pada umumnya jamur menempati beberapa jenis habitat yaitu tanah, kayu, serasah, kotoran hewan dan lain lain. Jenis ekosistem yang dapat ditumbuhi jamur adalah hutan, karena hutan memiliki tingkat kelembapan yang tinggi sehingga jamur mudah beradaptasi (Annisa dkk., 2017). Hutan memberikan berbagai manfaat baik secara langsung maupun tidak langsung, secara ekologi hutan adalah kesatuan ekosistem berupa hamparan lahan berisi sumber daya alam hayati berupa biotik dan abiotik yang didominasi oleh pepohonan dalam persekutuan alam lingkungannya, yang satu dengan yang lainnya tidak dapat di pisahkan (UU RI No.41 1999) (Indriyanto, 2012).

Jamur merupakan organisme eukariotik, berspora, tidak berklorofil, bereproduksi secara seksual dan aseksual. Jamur berdasarkan ukuran tubuhnya ada yang makroskopis yaitu jamur yang berukuran besar, sehingga dapat di lihat dengan mata telanjang dan ada juga jamur mikroskopis yaitu jamur berukuran kecil dan hanya dapat di lihat dengan alat bantu mikroskop. Beberapa jamur ada yang dapat konsumsi bahkan ada yang berkhasiat obat namun juga ada yang bersifat racun. Jamur yang dapat di konsumsi mempunyai kandungan garam mineral yang tinggi dari pada yang dikandung dalam daging sapi atau daging domba (Darwis dkk., 2011).

Jamur banyak ditemukan pada kayu lapuk, seresah dan tanah. Jamur dapat menjadi parasit pada tumbuhan yang masih hidup. Dari sisi ekologi, jamur di dalam hutan berperan sebagai dekompser bersama dengan bakteri dan beberapa spesies protozoa, sehingga banyak membantu proses dekomposisi bahan organik untuk mempercepat siklus materi dalam ekosistem hutan. Dengan demikian, jamur ikut membantu menyuburkan tanah melalui penyediaan nutrisi bagi tumbuhan sehingga hutan tumbuh dengan subur (Tampubolon, 2010).

Bukit Gatan merupakan bagian dari kelompok Hutan Lindung Bukit Cogong, dimana Bukit Cogong terbagi menjadi 3 bagian yaitu Bukit Cogong I (Bukit Besar), Bukit Cogong II (Bukit Botak), dan Bukit Cogong III (Bukit Gatan). Menurut Kesatuan Pengelolaan Hutan Produksi (KPHP) Benakat Bukit Cogong. Bukit Gatan memiliki luas sebesar $\pm 563,33$ Ha. Bukit Gatan terletak di Kecamatan STL Ulu terawas Kabupaten Musi Rawas. Bukit Gatan merupakan kawasan hutan lindung di bawah kewenangan Kesatuan Pengelolaan Hutan Produksi (KPHP) Benakat Bukit Cogong yang berada di Megang Sakti Kabupaten Musi Rawas. (Cahyono, 2013).

Tujuan penelitian ini adalah untuk menganalisis jenis-jenis jamur makroskopis di 
Bukit Gatan Kabupaten Musi Rawas Provinsi Sumatera Selatan.

\section{METODE}

Penelitian ini dilakukan pada bulan MeiJuli 2020 di Bukit Gatan kabupaten Musi Rawas. Metode penelitian ini adalah deskritif kualitatif yang bersifat survei atau eksploratif dengan metode pengambilan sampel yang menggunakan satu jalur pendakian umum. Pengamatan dilakukan pada area kiri dan kanan jalur pada jarak sampai dengan 5-10 meter (Tergantung kondisi medan) (Lingga, dkk, 2019).

Didalam prosedur penelitian ini, peneliti membahas tentang metode dan teknik pengumpulan data melalui:

1. Observasi dan Pengamatan, yang di lakukan di jalur pendakian pada kawasan Bukit Gatan Kecamatan STL Ulu Terawas Kabupaten Musi Rawas. Pada tahap observasi ini peneliti melakukan pengamatan langsung untuk melihat keanekaragaman jenis-jenis jamur Makroskopisyang ada di sekitar jalur pendakian Bukit Gatan Kecamatan STL Ulu Terawas Kabupaten Musi Rawas.

2. Dokumentasi, data jenis jamur Makroskopis yang terdapat di lokasi penelitian yang telah terkumpul di buktikan dengan fakta keberadaan di lapangan dan di lakukan proses mendokumentasikan.
3. Wawancara, dilakukan peneliti dengan cara mewawancarai warga sekitar yang berada di lokasi penelitian, Kesatuan Pengelolaan Hutan Produksi (KPHP).

4. Mengukur Faktor Lingkungan Abiotik, Kegiatan ini meliputi: $\mathrm{pH}$ tanah, suhu lingkungan, kelembapan tanah, intensitas cahaya dan ketinggian.

5. Tahap pelaksanaan pengambilan sampel, lokasi pengambilan sampel dilakukan di jalur pendakian Bukit Gatan Kecamatan STL Ulu Terawas Kabupaten Musi rawas. Sampel diambil secara langsung oleh peneliti dan langsung mencatat deskripsi dari jenis sampel jamur yang telah ditemukan, pengambilan sampel di lakukan satu minggu sekali selama satu bulan. Sampel yang didapat kemudian didokumentasikan.

6. Sampel yang didapat kemudian dibawa ke laboratorium Biologi STKIP PGRI Lubuklinggau untuk dilakukan identifikasi.

\section{HASIL DAN PEMBAHASAN}

Berdasarkan hasil penelitian yang telah dilakukan peneliti. Ditemukan sebanyak 21 spesies jamur yang termasuk kedalam 3 Kelas, 9 Ordo, 13 Famili, dan 17 Genus. Jenis-jenis jamur yang ditemukan dalam penelitian ini dapat dilihat pada Tabel 1 berikut: 
Biotropic Tahun 2021, Vol.5 (No.1): 21- 28

Eksplorasi Jenis Jamur Makroskopis di Kawasan Bukit Gatan Kabupaten Musi Rawas Provinsi Sumatera

Selatan

Tabel 1. Jenis Jamur Makroskopis Di Kawasan Bukit Gatan Kabupaten Musi Rawas Provinsi Sumatera Selatan

\begin{tabular}{|c|c|c|c|c|}
\hline Kelas & Ordo & Famili & Genus & Spesies \\
\hline Pezizomycetes & Pezizales & Sarcoscyphaceae & Cookeina & Cookeina sulcipes \\
\hline \multirow[t]{2}{*}{ Sordariomycetes } & \multirow[t]{2}{*}{ Xylariales } & \multirow[t]{2}{*}{ Xylariaceae } & Daldinia & Daldinia conentria \\
\hline & & & Xylaria & Xylaria longipes \\
\hline \multirow[t]{17}{*}{ Agaricomycetes } & \multirow[t]{5}{*}{ Agaricales } & \multirow[t]{2}{*}{ Pleurotaceae } & \multirow[t]{2}{*}{ Pleurotus } & Pleurotus ostreatus \\
\hline & & & & Pleurotus pulmonarius \\
\hline & & Agaricaceae & Lepiota & Leptiota brunneoincarnata \\
\hline & & Marasmiaceae & Marasmius & Marasmius candidus \\
\hline & & Schizophyllaceae & Schizophyllum & Schizophyllum commune \\
\hline & \multirow[t]{6}{*}{ Polyporales } & Ganodermataceae & Ganoderma & $\begin{array}{l}\text { Ganoderma sp } \\
\text { Ganoderma lucidum }\end{array}$ \\
\hline & & \multirow[t]{5}{*}{ Polyporaceae } & Earliella & Earliella scabrosa \\
\hline & & & \multirow[t]{2}{*}{ Lentinus } & Lentinus triginus \\
\hline & & & & Lentinus strigosus \\
\hline & & & Trametes & Trametes pubescens \\
\hline & & & Hirchioporus & Hirchioporus abietinus \\
\hline & Auriculariales & Auriculariaceae & Auricularia & Auricularia auricula \\
\hline & Geastrales & Geastraceae & Geastrum & Geastrum saccatum \\
\hline & Canthareliales & Tricholomataceae & Clitocybe & Clitocybe salmonilamella \\
\hline & Phallales & Phallaceae & Phallus & Phallus indusiatus \\
\hline & \multirow[t]{2}{*}{ Hymenochaetales } & \multirow[t]{2}{*}{ Hymenochaetaceae } & \multirow[t]{2}{*}{ Coltricia } & Coltricia cinamomea \\
\hline & & & & Coltricia perennis \\
\hline
\end{tabular}

Berdasarkan hasil penelitian Jenis-jenis Jamur Makroskopis yang telah dilakukan dari observasi dan wawancara di Bukit Gatan Kabupaten Musi Rawas jenis-jenis jamur yang ditemukan sebanyak 21 jenis jamur makroskopis yang termasuk kedalam 3 kelas, 9 ordo, 13 famili dan 17 genus. Jenis jamurjamur tersebut diantaranya, Lentinus strigosus, Daldina concentrica, Marasmius candidus, Xylaria longipes, Pleurotus pulmonarius, Trametes pubescens, Earliella scabrosa, Schizophyllum commune, Cookeina sulcipes, Auricullaria auricula, Hirchioporus abietinus, Geastrum saccatum, Lepiota brunneoincarnata, Pleurotus ostreatus, Ganoderma lucidum, Ganoderma sp, Lentinus triginus, Clitocybe salmonilamella, Coltricia perennis, Coltriciacinamomea, Entoloma procerum, dan Phallus indusiatus. Jamur-jamur tersebut ada yang dapat dikonsumsi dan ada yang tidak dapat dikonsumsi.

Menurut Annisa dkk. (2017) jamur yang bisa dikonsumsi adalah jamur yang pada umumnya tidak memiliki warna yang mencolok, tidak memiliki bau dan terdapat gigitan organisme lain pada jamur. Berdasarkan hasil penelitian yang telah dilakukan ada 7 jenis jamur yang dapat dikonsumsi, yaitu Lentinus strigosus, Pleurotus pulmonarius, Schizophllum commune, Cookeina sulcipes, Auricularia auricula, Pleurotus ostreatus, dan Phallus indusiatus. Hal ini sependapat dengan Darwis, dkk. (2011) yang menyatakan bahwa hasil 
Biotropic Tahun 2021, Vol.5 (No.1): 21- 28

Eksplorasi Jenis Jamur Makroskopis di Kawasan Bukit Gatan Kabupaten Musi Rawas Provinsi Sumatera

Selatan

identifikasi yang sudah dilakukan, jenis jamur yang dapat dikonsumsi yaitu Auricularia judae, Auricularia lacteal, Auricularia polytricha, Favolaaschia sp, Schyzophyllum commune, Pleurotusostreastus, Pleurotus sapidus dan Omphalatus sp. Sedangkan menurut Annisa, dkk (2017) menyatakan bahwa hasil identifikasi yang sudah sudah dilakukan, jamur yang bisa dijadikan bahan makanan yaitu Auricularia auricula, Auricularia judae, Phallus indusiatus, dan Phallus populinus.
Jamur yang paling banyak ditemukan dalam penelitian ini adalah jamur dari ordo Polyporales dan Ordo Agaricales. Ordo Polyporales merupakan salah satu ordo yang termasuk kedalam kelas Basidiomycetes. Jamur yang termasuk kedalam ordo Polyporales ada 7 jenis yaitu Earliella scabrosa, Ganoderma sp, Ganoderma lucidum, Lentinus triginus, Lentinus strigosus, Trametes pubescens, dan Hirchioporus abietinus.

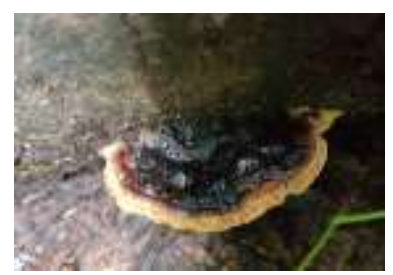

Earliella scabrosa

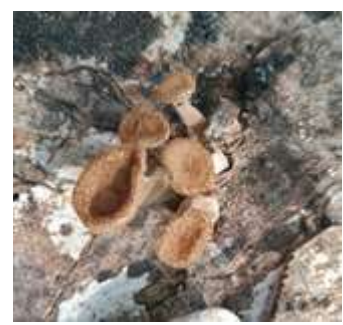

Lentinus strigosus,

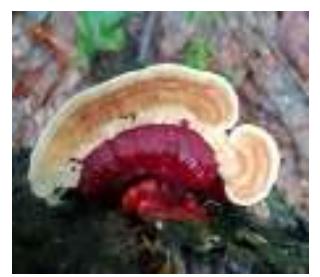

Ganoderma lucidum,

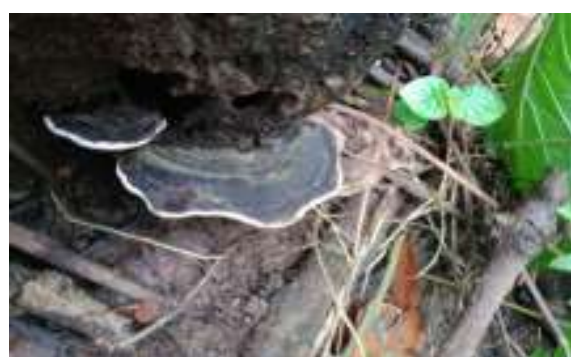

Hirchioporus abietinus.

\section{Lentinus triginus,}

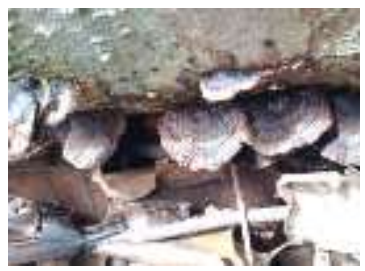

Ganoderma sp,

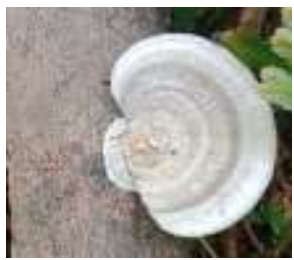

Trametes pubescens,

Gambar 1. Jamur Yang Sering Ditemukan di Kawasan Kawasan Bukit Gatan Kabupaten Musi Rawas Provinsi Sumatera Selatan

Jenis jamur Polyporales banyak ditemukan di area penelitian karena jenis jamur tersebut mampu beradaptasi dengan baik pada jalur pendakian Bukit Gatan hutan lindung Bukit Cogong III kabupaten Musi Rawas yang memiliki suhu $29^{\circ} \mathrm{C}-31^{\circ} \mathrm{C}$ sesuai dengan kebutuhan jamur dan banyaknya ‘ pohon ataupun kayu lapuk/mati sebagai tempat tumbuhnya jamur. Hal ini sependapat dengan Purwanto, dkk (2017) menyatakan bahwa jenis jamur dari ordo Polyporales merupakan kelompok jamur yang memiliki banyak spesies dan sering ditemukan karena jamur ini tumbuh pada substrat serasah ataupun kayu di hutan, serta 
Biotropic Tahun 2021, Vol.5 (No.1): 21- 28

mampu beradaptasi pada kondisi lingkungan yang kurang mendukung untuk pertumbuhannya. Sedangkan menurut Hiola (2011) menyatakan bahwa jenis jamur ordo Polyporales merupakan jenis jamur yang banyak dijumpai, karena jamur tersebut biasanya tumbuh pada kayu yang masih hidup maupun yang telah mati atau lapuk, dan sebagian jenisnya dapat beradaptasi dengan baik terhadap perubahan lingkungan.

Jenis jamur dari ordo Agaricales merupakan ordo yang memiliki anggota spesies paling banyak setelah ordo Polyporales. Jamur yang termasuk kedalam Ordo Agaricales ada 5 jenis spesies jamur yang ditemukan yaitu Pleurotus ostreatus, Pleurotus pulmonarius, Leptiota brunneoincarnata, Marasmius candidus, dan Schizophyllum commune. Menurut Tampubalon (2012) menyatakan bahwa Ordo Agaricales merupakan kelompok jamur yang sering ditemukan dengan bentuk seperti payung.

Jamur yang paling sedikit ditemukan pada penelitian ini yaitu jamur dari ordo Xylariales hanya terdapat 2 jenis jamur yaitu Daldinia conentria dan Xylaria longipes.

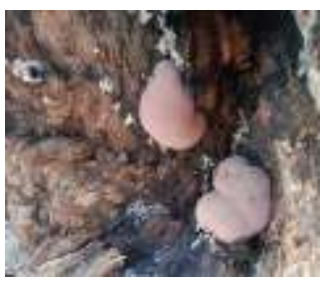

Daldinia conentria

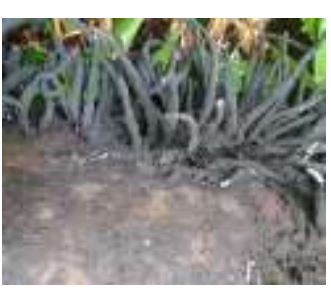

Xylaria longipes
Gambar 2. Jamur yang jarang ditemukan di Kawasan Kawasan Bukit Gatan Kabupaten Musi Rawas Provinsi Sumatera Selatan
Ordo Hymenochaetales terdapat 2 jenis jamur yaitu Coltricia cinamomea dan Coltricia perenis. Ordo Pezizales terdapat 1 jenis jamur yaitu Cookeina sulpipes. Ordo Auriculariales terdapat 1 jenis jamur yaitu Auricularia auricula. Ordo Geastrales terdapat 1 jenis jamur yaitu Geastrum saccatum. Ordo Canthareliales yaitu Clitocybe salmonilamella. Ordo Phallales terdapat 1 jenis jamur yaitu Phallus indusiatus. Hal ini terjadi karena jenisjenis jamur dari ordo ini ditemukan pada dataran tinggi dan kondisi lingkungan yang kering, sehingga jamur yang ditemukan sedikit. Hal ini sependapat dengan Khayati dan Warsito (2016) menyatakan bahwa penyebab jamur sedikit ditemukan karena kekurangnya pohon-pohon yang menaungu lantai hutan akibat penebangan hutang sehingga intensitas cahaya yang masuk semakin banyak, sehingga membuat serasahserasah dauh yang tidak ternaungi menjadi kering dan tidak lembab lagi sehingga jamur tidak dapat tumbuh. Sedangkan menurut Ulya (2017) menyatakan bahwa faktor lingkungan sangat berpengaruh pada penyebaran dan pertumbuhan suatu organisme, yaitu setiap spesies hanya bisa hidup dengan kondisi abiotik tertentu yang berada dalam kisaran toleransi yang cocok bagi organisme tersebut.

Faktor abiotik sangat mempengaruhi pertumbuhan jamur, jamur dapat tumbuh pada kisaran toleransi tertentu dan pada kondisi yang berbeda. Suhu merupakan salah satu faktor abiotik yang sangat mempengaruhi pertumbuhan jamur, hasil dari 
pengukuran suhu yang mempengaruhi pertumbuhan jamur pada penelitian yang telah dilakukan yaitu berkisar antara $29^{\circ} \mathrm{C}$ $31^{\circ} \mathrm{C}$ dan termasuk pada suhu optimum untuk pertumbuhan jamur. Hal ini sesuai dengan yang diungkapkan oleh Purwanto dkk. (2017) yang menyatakan bahwa suhu optimum untuk pertumbuhan jamur adalah $25^{\circ} \mathrm{C}-35^{\circ} \mathrm{C}$.

Selain suhu, kelembaban juga merupakan salah satu faktor abiotik yang mempengaruhi pertumbuhan jamur. Kelembaban tanah pada area penelitian antara 30\%-70\%. Dengan demikian area Bukit Gatan cocok untuk pertumbuhan jamur. Hal ini sesuai dengan yang diungkapkan oleh Khayati (2016) kelembaban optimum untuk pertumbuhan jamur yaitu $70-90 \%$. Faktor abiotik $\mathrm{pH}$ juga berpengaruh pada pertumbuhan jamur hasil pengukuran $\mathrm{pH}$ tanah yang dilakukan pada lokasi penelitian bersifat asam hingga netral pada kisran 6-7. Sesuai dengan pendapat Darwis dkk. (2011) $\mathrm{pH}$ optimum untuk pertumbuhan jamur yaitu 6,5-7,4. Intensitas cahaya juga berpengaruh pada pertumbuhan jamur, hasil pengukuran yang telah dilakukan diarea penelitian yaitu 200 lux.

Selain itu ketinggian juga mempengaruhi pertumbuhan jamur, hasil pengukuran pada area penelitian yaitu 72-241 mdpl. Menurut Warisno dan Dahana (2010), ketinggian suatu tempat dapat menentukan Suhu udara, intensitas cahaya matahari dan curah hujan, pada akhirnya mempengaruhi pertumbuhan tanaman, dalam hal ini juga akan berdampak pada pertumbuhan jamur. Sedangkan Menurut Darwis dkk. (2011) menyatakan bahwa, ketinggian suatu wilayah juga menentukan jamur yang hidup di wilayah tersebut. Semakin tinggi suatu wilayah maka jamur yang tumbuh juga semakin sedikit. Hal itu terjadi karena kurangnya kandungan air yang terdapat di wilayah dataran tinggi.

\section{KESIMPULAN}

Berdasarkan hasil penelitian yang dilakukan, dapat disimpulkan bahwa jenisjenis jamur yang ditemukan di Bukit Gatan Kabupaten Musi Rawas diperoleh 2 divisi, 3 Kelas, 9 ordo, 13 famili, 17 genus dan 21 spesies.

\section{DAFTAR PUSTAKA}

Annissa, I., Ekamawanti, H. A., dan Wahdina. 2017. Keanekaragaman Jenis Jamur Makroskopis Di Arboretum Sylva Universitas Tanjungpura. Jurnal Hutan Lestari. 5 (4), 969-977. Sumber: http://jurnal.untan.ac.id/index.php/j mfkh/article/view/22874/18136.

Cahyono, E. 2013. Valuasi Ekonomi Hutan Lindung Bukit Cogong Kabupaten Musi Rawas Provinsi Sumatera Selatan. Tesis. Program Studi Pasca Sarjana Pengelolaan Sumberdaya Alam dan Lingkungan (S-2). Fakultas Pertanian Universitas. Bengkulu.Sumber: http://repository.unib.ac.id/1357/.

Darwis, W., Desnalianif, dan Supriati, R. 2011. Inventarisasi Jamur Yang Dapat Dikonsumsi dan Beracun Yang Terdapat Di Hutan dan Sekitar Desa Tanjung Kemuning Kaur Bengkulu. Jurnal Konservasi Hayati, 7 (2), 1-8. Sumber:http://repository.unib.ac.id/ 7865/1/Jurnal\%20welly-rochmahdesnalianif\%200ktober\%202011.pdf. 
Biotropic Tahun 2021, Vol.5 (No.1): 21- 28

Hiola, S. F. 2011. Keanekaragaman Jamur Basidiomycota di Kawasan Gunung Bawakaraeng (Studi Kasus: Kawasan Sekitar Desa Lembanna Kecamatan Tinggi Moncong Kabupaten Gowa. Jurnal Bionature, 12 (2):93:100. Sumber:https://ojs.unm.ac.id/bionat ure/article/view/1402.

Indriyanto. 2012. Ekologi Hutan. Jakarta: PT Bumi Aksara.

Khayati, L dan Warsito, H. 2012. Keanekaragaman Jamur Kelas Basidiomycetes Di Kawasan Lindung KPHP Sorong Selatan. Prosiding syimbion (Syimposium on Biology Education). Papua: Universitas Ahmad Dahlan, 213-222. Sumber: http://symbion.pbio.uad.ac.id/prosidi ng/prosiding/ID_301_Lisna_Revisi_Ha 1\%20213-222.pdf.

Lingga, R., Gabriela, F. V., dan Darlingga, M. 2019. Keanekaragaman Jamur Makroskopis Di Kawasan Taman Wisata Alam Permisan, Kabupaten Bangka Selatan. Jurnal Penelitian Biologi, Botani, Zoologi dan Mikrobiologi, 4 (1), 18-24. Sumber: https://journal.ubb.ac.id/index.php/e kotonia/article/view/1011.

Purwanto,B.P., Zaman,N.M., Yusuf, M., Romli, M., Syafi'i, I., Hardhaka, T., Fuadi, F.B., Saikhu, A.R, Ar Rouf,A.S., Adi, A., Laily, Z., dan Yugo, M.H. 2017. Inventarisasi Jamur Makroskopis Di Cagar Alam Nusakambangan Timur Kabupaten Cilacap Jawa Tengah. Jurnal Proceeding Biology Education Conference, 14 (1): 79-82. Sumber: https://jurnal.uns.ac.id/prosbi/articl e/view/18700.

Tampubolon, S. 2010. Keanekaragaman Jamur Makroskpis di Hutan Pendidikan Universitas Sumatera Utara desa Tongkoh kabupaten Karo Sumatera Utara. Skripsi. Program Studi Kehutanan. Sumber: http://repository.usu.ac.id/handle/1 $23456789 / 52852$.

Ulya, A. 2017. Biodiversitas Dan Potensi Jamur Basidiomycota di Kawasan Kasepuhan Cisungsang, Kabupaten Lebak, Banten. Journal of Biology, 10(1): $\quad$ 9-16. Sumber: http://journal.uinjkt.ac.id/index.php/ kauniyah/article/view/4513.

Warisno dan Dahana. 2010. Peluang Usaha dan Budidaya Cabai. Jakarta: Gramedia Pustaka Utama 